\title{
AiMT
}

Advances in Military Technology

Vol. 12, No. 1 (2017), pp. 21-32

ISSN 1802-2308, eISSN 2533-4123

DOI 10.3849/aimt.01144

\section{Battery Voltage Limit Analysis with Support Vector Machine and Fuzzy Logic}

\author{
R. Szabolcsi ${ }^{1 *}$ and J. Menyhárt ${ }^{2}$ \\ ${ }^{1}$ Óbuda University, Budapest, Hungary \\ ${ }^{2}$ University of Debrecen, Debrecen, Hungary \\ The manuscript was received on 15 September 2016 and was accepted \\ after revision for publication on 22 February 2017.
}

\begin{abstract}
:
The efficiency and the range of modern electric vehicles are crucial points in their design. Designers and engineers are highly motivated to find solutions to these problems, or, as a rule, to improve existing electrical systems. Considerable number of modern batteries is available for use in electric vehicles and robots. The authors will propose new technology and new methods to use batteries with better efficiency. The authors propose to use the Support Vector Machine and Fuzzy logic in a new approach, which is the battery technical status management. The results show that it is possible to use these two methods simultaneously and they can ensure better results at the operation site.
\end{abstract}

\section{Keywords:}

autonomous vehicle, UGV, SVM-Classification, fuzzy logic, battery

\section{Introduction}

Nowadays one uses more and more intelligent vehicles and tools. These kinds of machines and vehicles get a high priority in industrial life and daily traffic. The engineers would like to prepare machines with higher efficiency. In modern industrial sites, companies use different Lean principles. Thanks to these principles, they can reach better Key Performance Indicators (KPI) systems and a better customer demand.

The engineers try to use different types of machine intelligence techniques to reach a better efficiency, such as fuzzy logic, neural networks, probability theory etc. In the previous works of the authors the lithium-polymer batteries monitored by Fuzzy logic have been exhaustively described.

The authors had leaned on measurements executed over an electrical system of the e-vehicle designed at University of Debrecen [1-2]. Based on these studies and experiences, a brand new operational strategy for the batteries and for the electrical machines

\footnotetext{
* Corresponding author: Institute of Mechatronics and Vehicle Engineering, Donát Bánki Faculty of Mechanical and Safety Engineering, Óbuda University, 1081 Budapest, Népszínház str. 8., Hungary. Phone: +36-1-666-5349, E-mail: szabolcsi.robert@bgk.uni-obuda.hu
} 
can be established. The battery parameters are very important for electric vehicles and machines. The motivation of the authors is to find ideal parameters for the batteries which can give a better efficiency with appropriate safety level.

During the development process, the authors work with Fuzzy logic and Support Vector Machine (SVM) which are parts of the artificial intelligence tool set. The paper will describe a method of Support Vector Machine and Fuzzy logic applied to support energy consumption management of electrical machines. The study presents preliminaries and related works, the new limits of battery voltage determined with SVM method and a Fuzzy analysis.

\section{Preliminaries and related works}

In the modern industrial life, companies use different techniques to improve their productivity. Currently, the most important corporate governance and management control philosophy is the Lean. The 'Just in Time' (JIT) and Milk Run systems are the most important logistic equipment. Thanks to these techniques, companies can reduce their production costs [3-5].

These techniques can help us to attain a high velocity of manufacturing but they are very sensitive in practice. Any mistake or failure in the system can result in outage in the production. It can make customers dissatisfied [3-5].

[3] and [4] had extensively demonstrated the theoretical background of JIT. [5] described a case study of a Just in Time system in automotive industry. The engineers have to design machines with better efficiency to reach the Just in Time goals. Companies use more and more robots for Milk Run and JIT systems, these robots work mainly with batteries.

Companies developed different types of battery management systems for robots and vehicles [6-8]. Few years ago, batteries were very heavy and complicated to use in a lot of industrial applications and vehicles, too. Today when the Li-batteries are cheaper and lighter than ever before, they get more attention in vehicle and robot industry. A great number of researchers and research topics work on different types of battery management units, batteries or fault diagnostics with artificial intelligence equipment [9-12].

[9] and [10] had duly demonstrated the results of the development of lithium batteries elaborated by Swedish researchers. [11] and [12] discussed investigations of fault diagnostics of Lithium-ion batteries and electric motors.

[13] has demonstrated MATLAB applications, moreover [14] was helpful in Fuzzy Logic and [15] Support Vector Machine (SVM) applications [15-20].

\section{Batteries' voltage analysis with Support Vector Machine (SVM) Method}

\subsection{Support Vector Machine Applied for Classification}

One of the most popular methods for classification is the Support Vector Machine. This method can make an optimal hyperplane to separate data [15, 19-21].

The vehicle and its electrical system under the investigation was a prototype electric vehicle (Fig. 1). The electrical energy system supplying the vehicle was based on 
the LiFeYPO4 batteries. The electrical system integrates two sets of 8 rechargeable batteries of the type of LiFeYPO4 serially connected in each sets to provide appropriate voltage level of 48 DC V (Fig. 2).

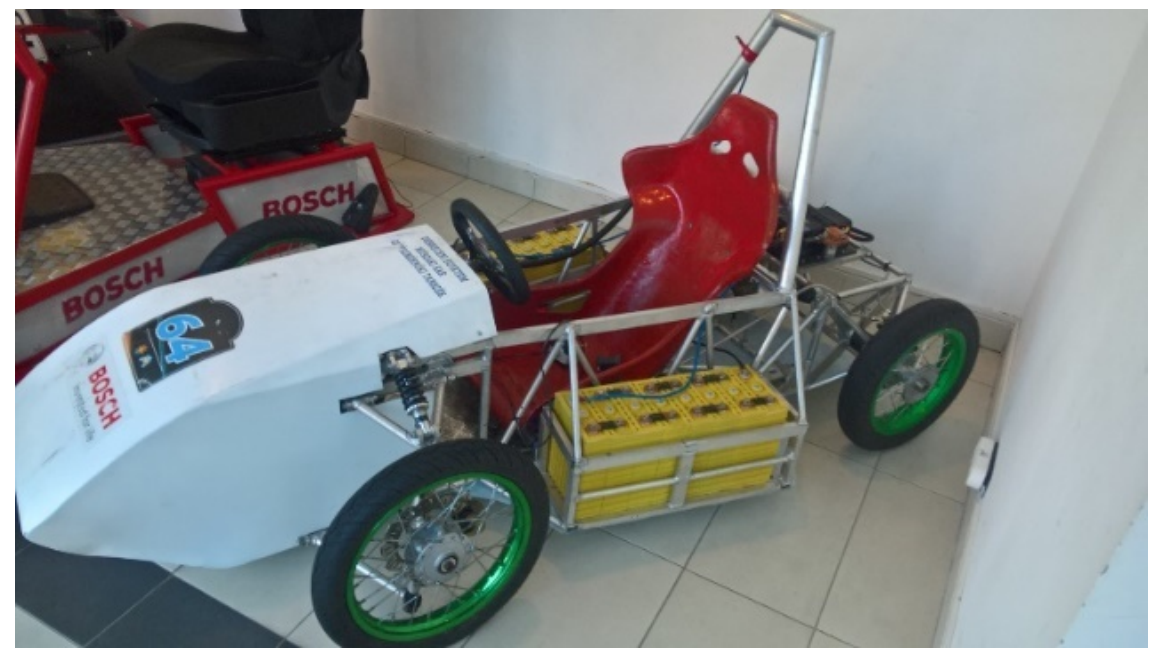

Fig. 1 Experimental electric vehicle

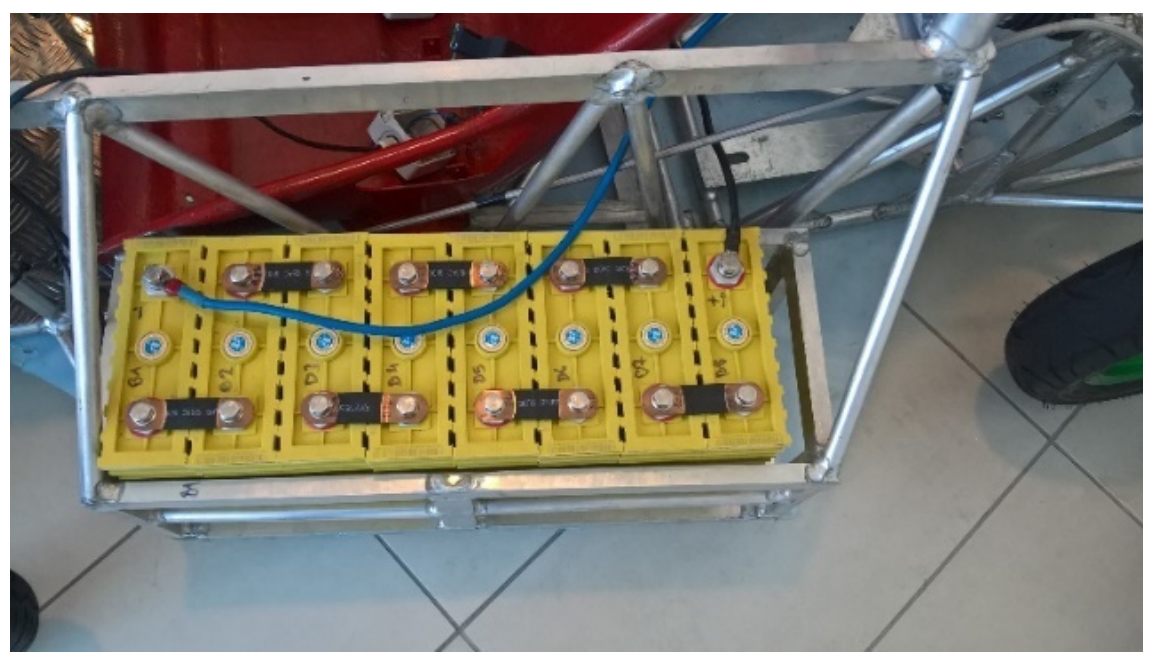

Fig. 2 E-vehicle System of batteries

The nominal voltage of a single battery is $3.2 \mathrm{~V}$. The recommended maximum and minimum voltages of the batteries are $3.55 \mathrm{~V}$ and $3 \mathrm{~V}$, respectively, and, these parameters are ensured by manufacturer of the batteries. The batteries were connected to a DC electric engine controller of the type of $48 \mathrm{~V} / 350$ A DC electric engine controller (Fig. 3). This controller managed the power and efficiency of the vehicle. The controller has high efficiency, good stability and a compact size. It uses PWM-technology and it can reverse the direction of the rotational motion of the electric motor. The electric motor is a DC $48 \mathrm{~V}$ and $4 \mathrm{~kW}$ electric motor. The vehicle uses a single DC motor to introduce mechanical energy ensuring movement of the e-machine. 


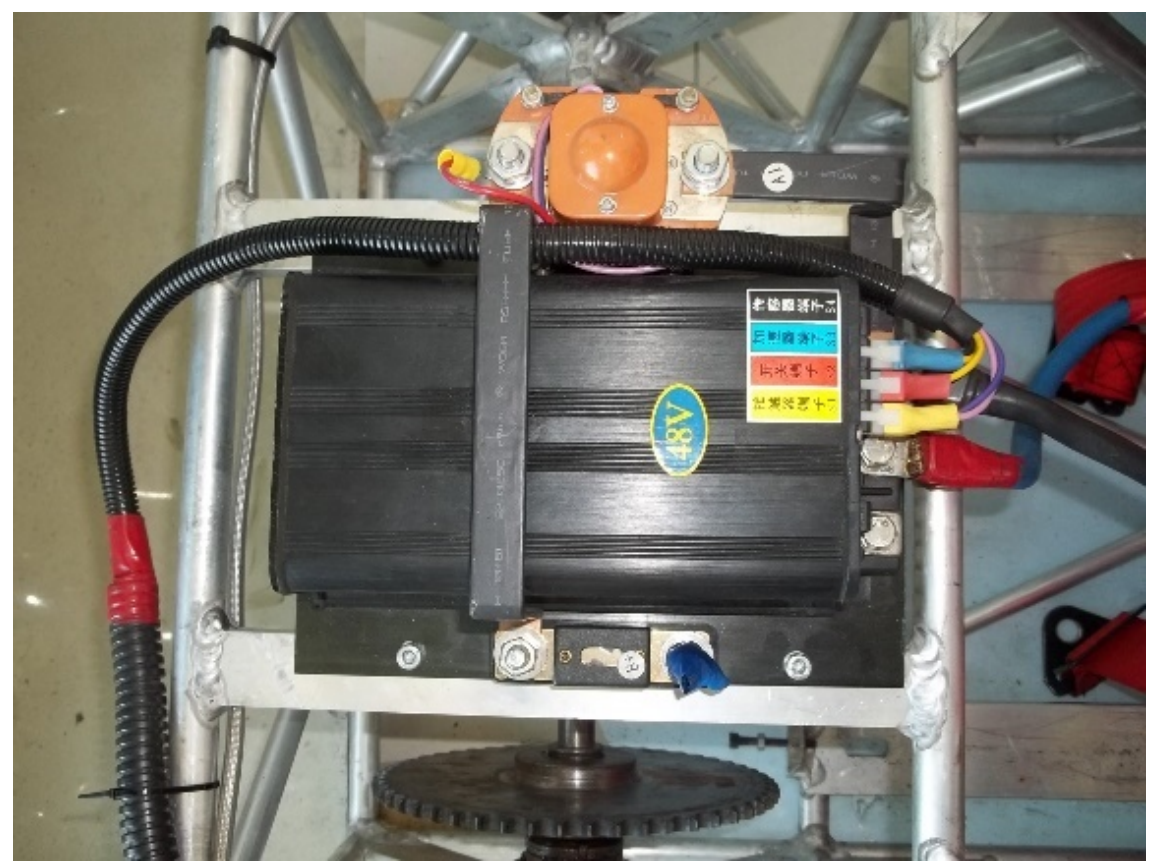

Fig. 3 The electric engine controller

During research work authors made voltage measurement using an Arduino device. The Arduino device is an open source electric controller and due to its simple programming and configuration properties today it is a very popular development platform [22-23].

Based on lessons learned from vehicle runs the developer team of the vehicle stated that batteries are able to work far out of their maintenance regimes ensured by manufacturers without any overheating, or, any other malfunctions threatening the energy supply system of the e-vehicle. To find the extended limits of the batteries' maintenance regimes, the developers' team agreed to involve ten full cycles of the batteries including charging and discharging processes into investigations. The results of the voltage measurement of the batteries' are tabulated in Table 1 .

The first finding must be done: results of the voltage measurements show a significant difference between the allowed and measured voltages. This practical data shows better efficiency in the use during competition runs.

Tab. 1 Practical and prescribed values

\begin{tabular}{|c|c|c|c|c|c|c|c|c|c|c|}
\hline Measurements & $\mathbf{1}$ & $\mathbf{2}$ & $\mathbf{3}$ & $\mathbf{4}$ & $\mathbf{5}$ & $\mathbf{6}$ & $\mathbf{7}$ & $\mathbf{8}$ & $\mathbf{9}$ & $\mathbf{1 0}$ \\
\hline $\begin{array}{c}\text { Measured Voltage } \\
\text { (upper), V }\end{array}$ & 3.600 & 3.680 & 3.690 & 3.700 & 3.740 & 3.750 & 3.781 & 3.820 & 3.830 & 3.833 \\
\hline $\begin{array}{c}\text { Maximum Voltage } \\
\text { Allowed (upper), V }\end{array}$ & \multicolumn{10}{|c|}{3.550} \\
\hline $\begin{array}{c}\text { Measured Voltage } \\
\text { (lower), V }\end{array}$ & 2.200 & 2.250 & 2.283 & 2.293 & 2.456 & 2.534 & 2.574 & 2.697 & 2.713 & 2.965 \\
\hline $\begin{array}{c}\text { Minimum Voltage } \\
\text { Allowed (lower), V }\end{array}$ & \multicolumn{10}{|c|}{3.000} \\
\hline
\end{tabular}


The authors used and modified [20] MATLAB script for the Support Vector Machine (SVM) analyses. Using this program the data are on a diagram which is easy to use in practice. The program is a linear classifier that is defined by a threshold value and a 2-dimensional weight vector. The MATLAB script uses the bioinformatics toolbox, which includes a svmtrain function [20]. Figure 4 describes the new upper Voltage limit of the batteries (3.665 V). The ' $\mathrm{x}$ ' axis is the 'Number of measurements [pcs]' the 'y' axis is the 'Voltage [V]'. The red crosses show the original or the prescribed Voltage data. The blue crosses show the tentative data. The SVM method can calculate a new optimal hyperplane, which is the new voltage limit.

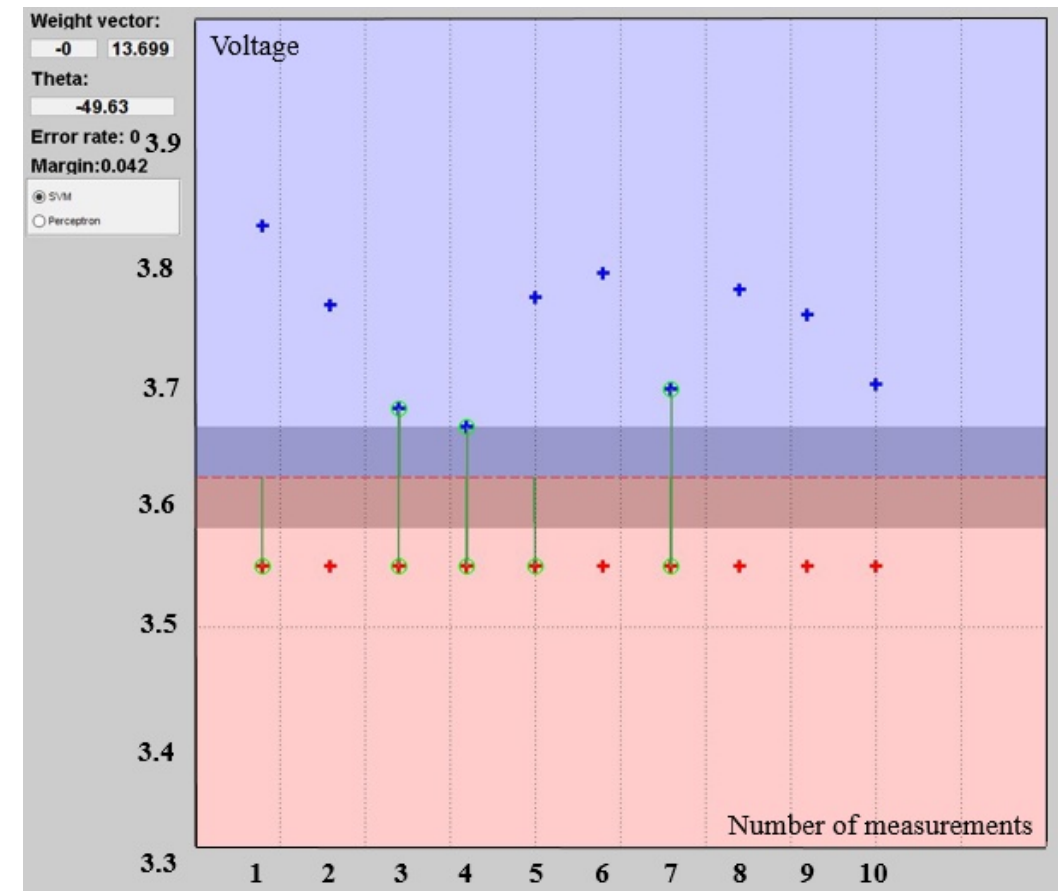

Fig. 4 SVM margins: upper limit

Fig. 5 shows the new margins of the lower voltage of the batteries $(2.75 \mathrm{~V})$.

In summary, these MATLAB calculations show that the batteries can work with wider limits than it is ensured by manufacturers with an appropriate level of safety $[15,17-20]$.

\subsection{Data Evaluation Using Fuzzy Logic}

The measured results show variance in practice $[1-2,14]$. The use of fuzzy logic enabled the authors to find a precise bounds of the batteries' regimes where they can work safely. The statistical data is shown in Tab. 2 [1-2].

Article [24] describes the main steps of Fuzzyfication and introduces the generally applied functions. The fuzzy membership functions make an imaging in the analyzed set and describe it in a $0 \div 1$ interval. The $\mu$ membership function describes the result of the analysis in a $0 \div 1$ interval. The $\mu$ values can take any result between 0 and 1 [24]. The general formula of $[1,24]$ determines the Fuzzy membership function of parameter tolerances in the following form: 


$$
\mu=\frac{1}{1+e^{a_{i}\left(b_{i}-x\right)}}
$$

where $x$ is the input parameter, $a_{i}$ and $b_{i}$ are scalar coefficients. From Eq. (1) it is easy to see that coefficients $a_{i}$ and $b_{i}$ can change the shape of the membership function. Coefficient $a_{i}$ affects the slope of the membership function, whilst coefficient $b_{i}$ determines the midpoint of the membership function. Calculation of the coefficients of Eq. (1) is exhaustively described in [24-27].

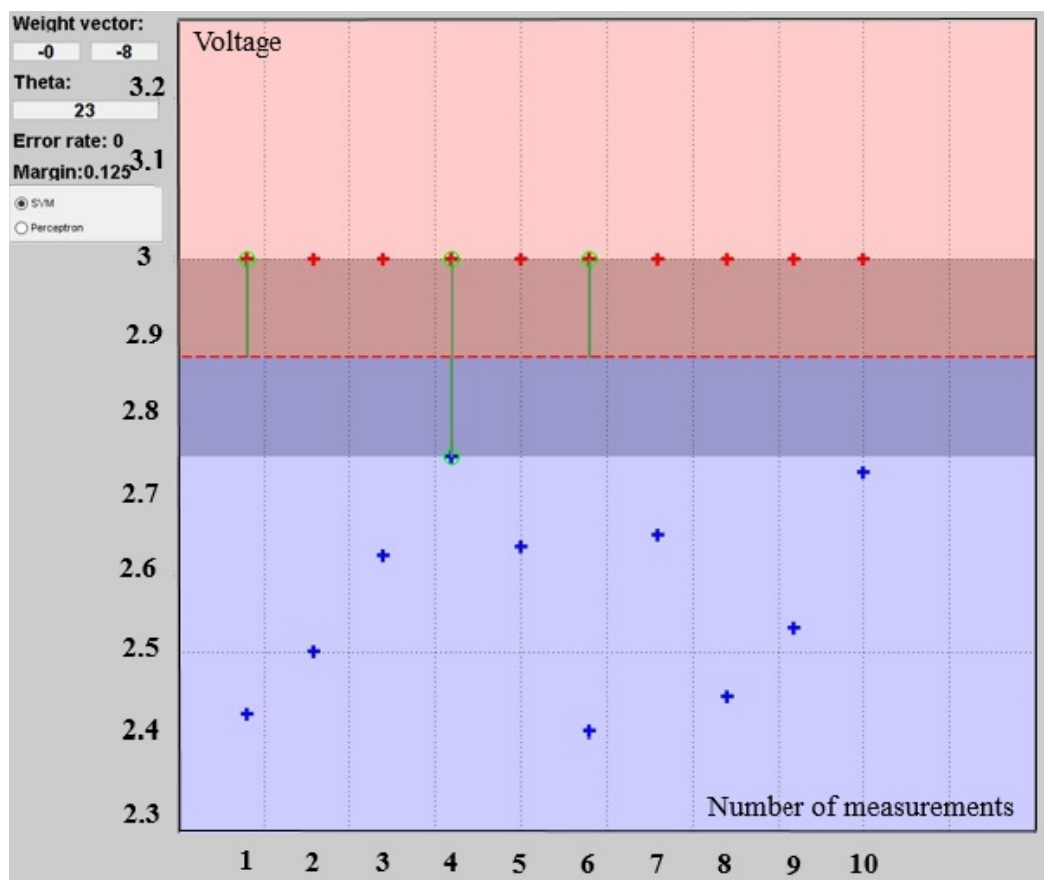

Fig. 5 SVM margins: lower limit

Tab. 2 Batteries Dataset

\begin{tabular}{|c|c|c|}
\hline & & Empirical value \\
\hline \multirow{3}{*}{$V_{\operatorname{maxSVM}}[\%]$} & Min & 100.00 \\
\hline & Max & 104.50 \\
\hline & Average & 102.13 \\
\hline \multirow{3}{*}{$\mathbf{V}_{\operatorname{minSVM}}[\%]$} & Min & 75.07 \\
\hline & Max & 65.48 \\
\hline & Average & 68.11 \\
\hline \multirow{3}{*}{$V_{\max }[\%]$} & Min & 100.00 \\
\hline & Max & 105.41 \\
\hline & Average & 104.85 \\
\hline \multirow{3}{*}{$V_{\min }[\%]$} & Min & 84.05 \\
\hline & Max & 61.97 \\
\hline & Average & 70.32 \\
\hline
\end{tabular}


The sigmoid function is a special mathematical function. It has an "S" shaped curve. This function has a positive derivate everywhere and it is a bounden differentiable real function. In another approach, the sigmoid function is a special case of the logical criteria. The function often takes values either on the range from 0 to 1 and / or from -1 to 1 . This property always depends on the preliminary defined convention. There is wide variety of the known sigmoid functions. The sigmoid functions have been used as an activation function or in artificial intelligence. The fuzzy logic often uses it when a detailed description is missing, in these cases the sigmoid function has an important role [24-27].

The coefficients of the Fuzzy membership function defined by Eq. (1) can be found in Table 3 [1-2].

Tab. 3 Calculated Coefficients

\begin{tabular}{|c|c|c|}
\hline Parameter (i) & $a_{i}$ & $b_{i}$ \\
\hline $\mathbf{V}_{\operatorname{maxSVM}}$ & 2.473 & 101.754 \\
\hline $\mathbf{V}_{\operatorname{minSVM}}$ & 1.776 & 73.055 \\
\hline $\mathbf{V}_{\max }$ & 2.552 & 104.995 \\
\hline $\mathbf{V}_{\min }$ & 1.665 & 69.566 \\
\hline
\end{tabular}

Figures 6 and 7 illustrate the membership functions which are calculated using coefficients tabulated in Tab. 3 [1-2].

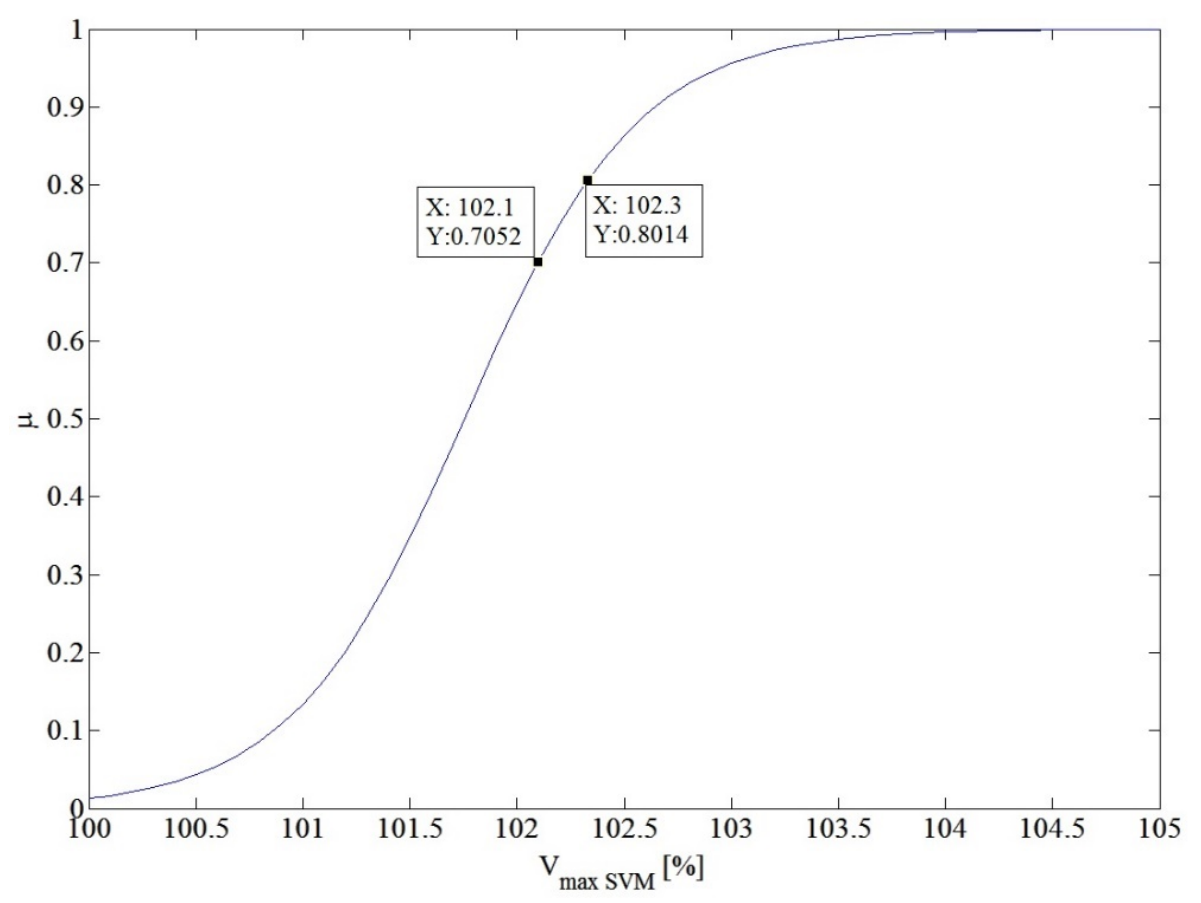

Fig. 6 Fuzzy membership function $V_{\max S V M}$ 


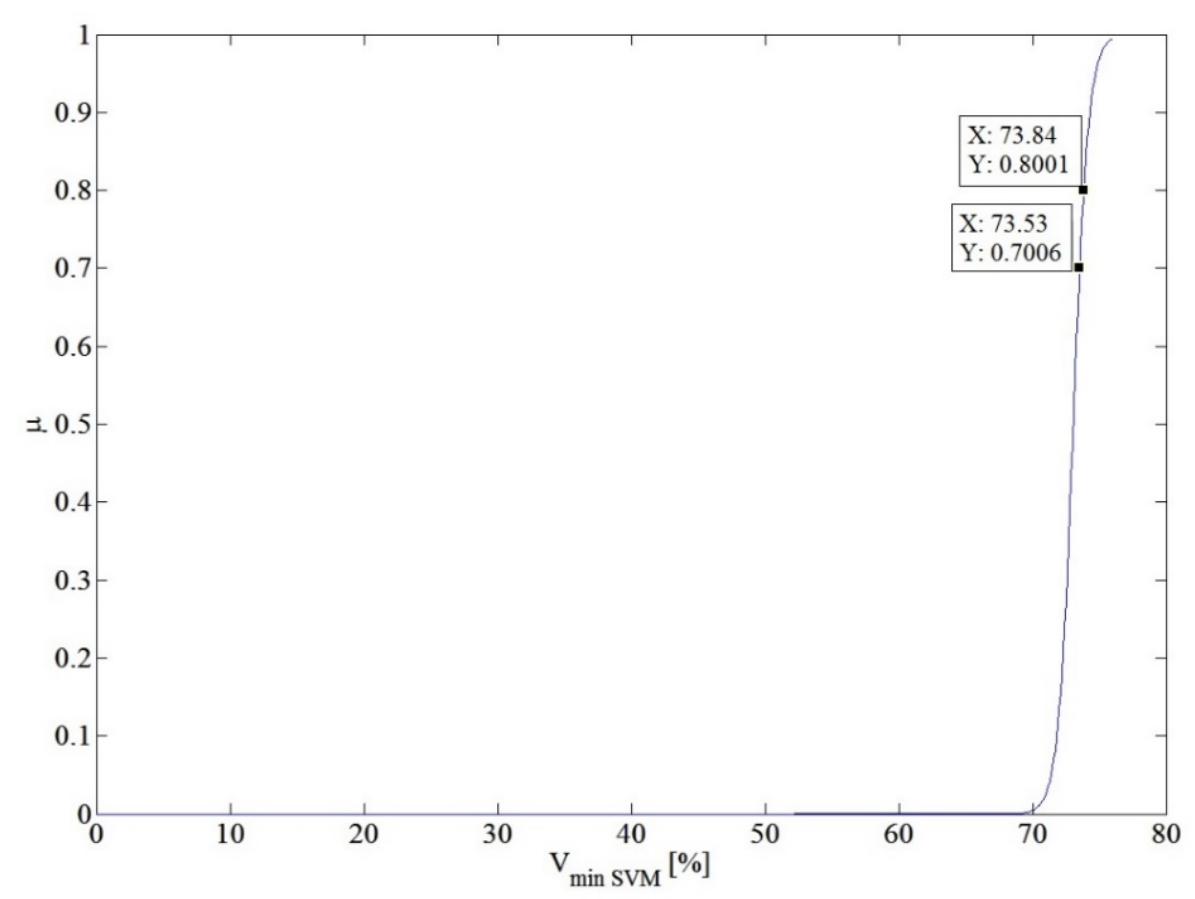

Fig. 7 Fuzzy membership function $V_{\text {minsvM }}$

\subsection{Results of the new acceptable Voltage parameter tolerances}

The maximum and minimum voltage levels are controlled by the Battery Management System (BMS) and when the batteries reach either higher or lower values of these limits, the BMS has to be activated.

There are two kinds of intervention of the BMS system can provide: it has to either start the charging process or stop it. The OR logical connection must be used between the criteria. The logical rule's true value surface is [1-2]:

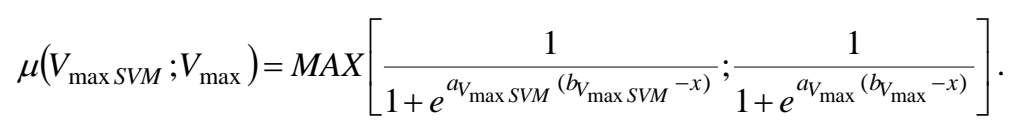

The BMS needs to start the charging process if the voltage is low. In this case, the OR logical rules have to be followed again. The true value surface is [1-2]:

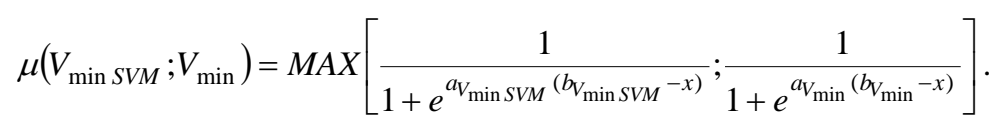

As it is shown by practical experience, the true values have been determined between $0.7 \div 0.8$. This shows that it can be dangerous if we exceed 0.8 during the batteries' charging process and/or immersion. Tables 4 and 5 tabulate the data for 0.7 and 0.8 , respectively [1-2]. 


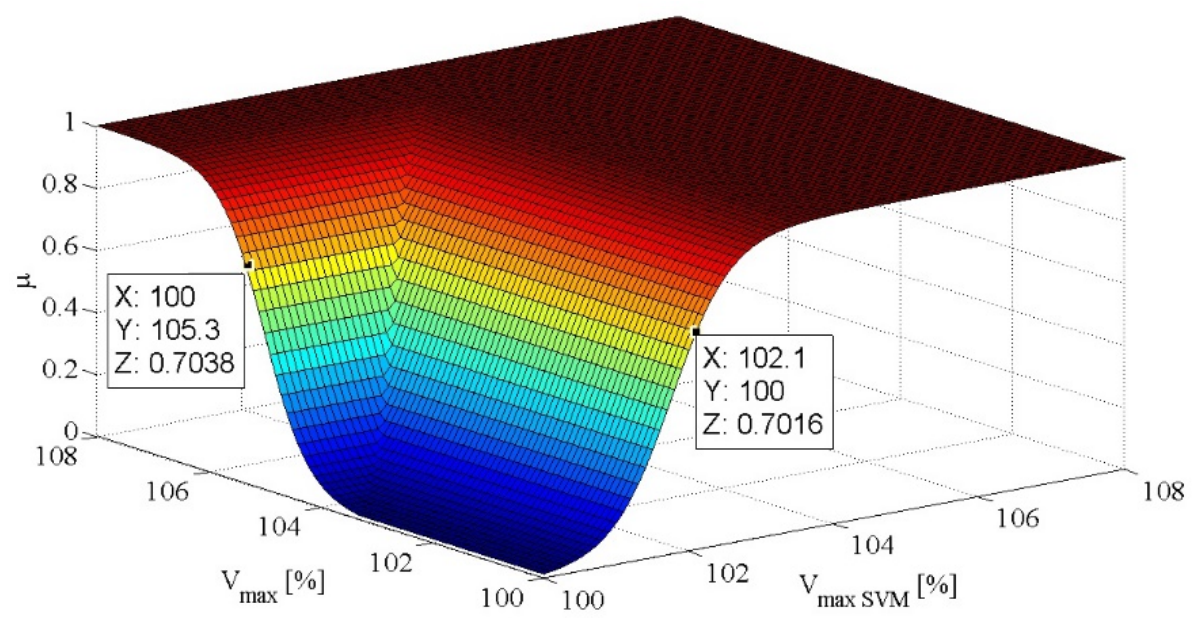

Fig. 8 The Fuzzy membership function of $V_{\max }$ vv

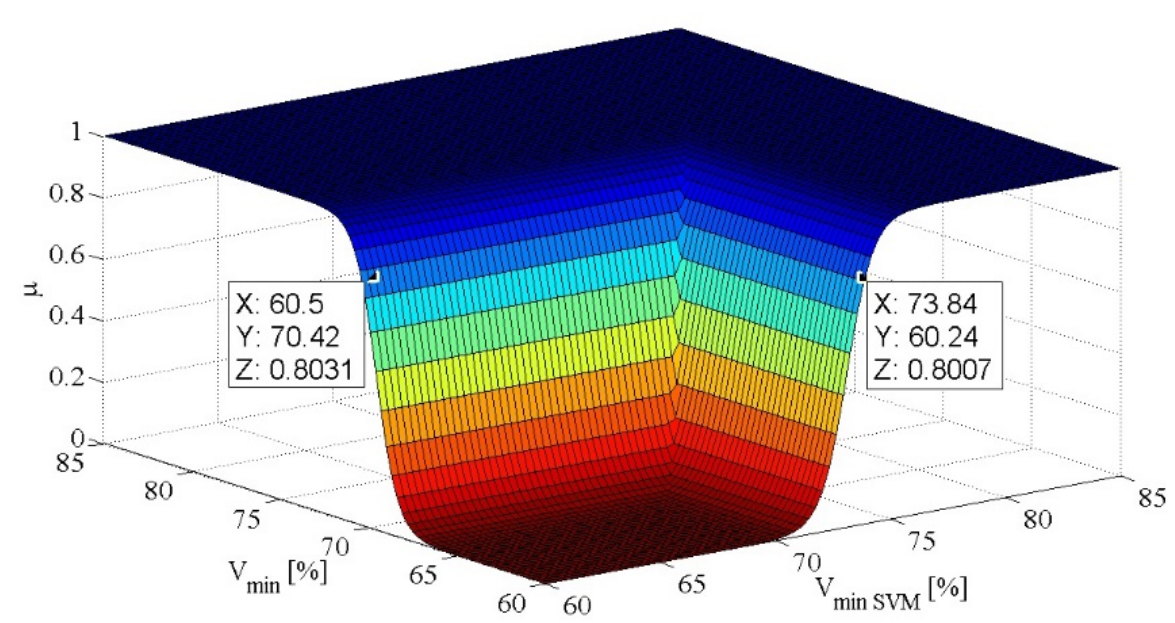

Fig. 9 Fuzzy membership function of $V_{\operatorname{minsVM}}$

Tab. $4 V_{\max }$ and $V_{\max S V M}$ Truth values

\begin{tabular}{|c|c|c|}
\hline \multirow{4}{*}{$V_{\max }$} & \multirow{2}{*}{$\mu=0.7$} & $102.10 \%$ \\
\hline & & $3.73 \mathrm{~V}$ \\
\hline & \multirow{2}{*}{$\mu=0.8$} & $102.30 \%$ \\
\hline & & $3.74 \mathrm{~V}$ \\
\hline \multirow{4}{*}{$V_{\operatorname{maxSVM}}$} & \multirow{2}{*}{$\mu=0.7$} & $105.30 \%$ \\
\hline & & $3.74 \mathrm{~V}$ \\
\hline & \multirow{2}{*}{$\mu=0.8$} & $105.50 \%$ \\
\hline & & $3.75 \mathrm{~V}$ \\
\hline
\end{tabular}


Tab. $5 V_{\min }$ and $V_{\operatorname{minSVM}}$ Truth values

\begin{tabular}{|c|c|c|}
\hline \multirow{2}{*}{$\mathbf{V}_{\min }$} & $\mu=0.7$ & $70.08 \%$ \\
\cline { 3 - 3 } & \multirow{2}{*}{$\mu=0.8$} & $2.49 \mathrm{~V}$ \\
\cline { 2 - 3 } & \multirow{2}{*}{$\mathbf{V}_{\text {minsVM }} \mu=0.7$} & $70.04 \%$ \\
\cline { 3 - 3 } & \multirow{2}{*}{$\mu=0.8$} & $2.50 \mathrm{~V}$ \\
\cline { 2 - 3 } & & $2.63 \%$ \\
\cline { 2 - 3 } & & $73.84 \%$ \\
\hline
\end{tabular}

\section{Conclusion}

The authors discussed the results of the technical status management of the Li-batteries using soft computing method. The conventional method of battery maintenance based on strict measurements of the voltages has been investigated. The basic hypothesis of the authors of the possible extension of upper and lower values of the voltages of the maintenance of the batteries has been proven.

Authors had established new logical rules for the Battery Management System to start to recharge the batteries, or, to stop charging process using SVM method and Fuzzy logic.

The authors analyzed Lithium batteries' data with MATLAB software. The Support Vector Machine simulations derived new voltage limits for the batteries both for its maximum and minimum values. These new limits ensure proper safety level during daily life.

The authors checked the batteries' parameter tolerances with Fuzzy logic after the SVM calculations. Using techniques described above the authors determined a brand new voltage limits for the batteries. The results showed that Fuzzy analysis can be effectively used if it is supported by the SVM analysis.

The use of Fuzzy logic and SVM produced better efficiency for the electrical system of electric vehicle. The new voltage limits of the batteries made a new perspective for the electric vehicle. The electrical system can ensure a better electric performance due to the extended battery voltage range. The vehicle can use this performance for a longer range, for better acceleration capabilities, or for reaching higher speeds, which are important features during competition runs.

\section{References}

[1] POKORÁDI, L. and MENYHÁRT, J. Electric Vehicles’ Battery Parameter Tolerances Analysis by Fuzzy Logic. In Proceedings of the $11^{\text {th }}$ IEEE International Symposium on Applied Computational Intelligence and Informatics SACI 2016. 2016, p. 361-364.

[2] SZABOLCSI, R. and MENYHÁRT, J. Diagnostics of the Batteries Technical Status Using SVM Method. Revista Academiei Fortelor Terestre REVISTA, 2016, vol. 2, p. 190-197.

[3] HONG-MO, D.Y. Just-In-Time Manufacturing, MGT2405, University of Toronto, Chapter 8, p. 1-13. [cited 2016-08-01]. Available from:

$<$ http://www.lancer.com.tw/attachments/367_ErpBook(8).pdf>. 
[4] KOOTANAEE, A.J., BABU, K.N., and TALARI, H.F. Just-in-Time Manufacturing System: From Introduction to Implement. International Journal of Economics, Business and Finance, 2013, vol. 1, No. 2, p. 7-25.

[5] HOU, B., CHAN, H.K. and WANG, X. A Case Study of Just-In-Time System in the Chinese Automotive Industry. In Proceedings of the World Congress on Engineering 2011. London: WCE. 2011, vol. 1.

[6] TORRES, D. Multi-Cell Li-Ion Battery Management System Using MSP430F5529 and bq76PL536 [Application Report]. MSP430 System Solutions, SLAA 2010, Texas Instruments.

[7] Texas Instruments Ltd.: Battery Management Solutions, Harves the Power of the world's energy, 2012. [cited 2016.08.01.] Available from: <www.ti.com/battery>.

[8] Rimac Automobili: Battery Management System. [cited 2016-08-01]. Available from: <http://www.rimac-automobili.com/media/2212/ra-bms-data-sheet.pdf>.

[9] FISK, H. and LEIJGARD, J. A Battery Management Unit (in English) [Master Thesis]. Goteborg, Sweden: University of Gothenburg, 2010.

[10] KLASS, V., BEHM, M. and LINDBERGH, G. State-of-health estimation of lithium-ion batteries in electric vehicles. T3:4 Battery system - Life model, Applied Electrochemistry, Department of Chemical Engineering and Technology, School of Chemical Science and Engineering, KTH Royal Institute of Technology, Swedish Hybrid Vehicle Centre, 2015.

[11] RAHMAN, MD A. and ANWAR, S. Electrochemical Model Based Fault Diagnosis of a Lithium Ion Battery using Multiple Model Adaptive Estimation Approach, Industrial Technology (ICIT) IEEE, 2015, p. 210-217.

[12] PÖYHÖNEN, S.: Support Vector Machines in fault diagnostics of electrical motors, [Research Report] Teknillinen Korkeakoulu, Tekniska Högskolan, Helsinki University of Technology, Control Engineering Laboratory, Espoo, 2002.

[13] SZABOLCSI, R. Computer Aided Design of Modern Control Systems, Miklós Zrínyi National Defense University, 2011, 415 p.

[14] POKORÁDI, L. Modelling of Systems and Signals (in Hungarian) Campus Publishing House, 2008, 242 p.

[15] FAZEKAS, I. Neural Networks (in Hungarian) University of Debrecen, Hungary, 2013, p. 93-123".

[16] MathWorks, [on line] Fuzzy Logic Toolbox [cited: 2013.11.28] Available from: <http://www.mathworks.com/products/fuzzy-logic/>.

[17] SVM Tutorial [on line] Support Vector Regression with $R$ [cited: 2016.01.05]. Available from: <http://www.svm-tutorial.com/2014/10/support-vectorregression-r/>.

[18] OWEN, W.J. The R Guide, Version 2.5, Department of Mathematics and Computer Science, University of Richmond, 2010.

[19] XIE, K. Support Vector Machine, Concept and MATLAB Build, ECE 480, Team 4. Available from: <http://www.egr.msu.edu/classes/ece480/capstone/spring11/group04/application_Kan.pdf> 
[20] MathWorks [on line] File Exchange, SVM Demo (Richard Stapenhurst) [cited: 2016.03.20] Available from:

<http://www.mathworks.com/matlabcentral/fileexchange/28302-svm-demo>

[21] VAPNIK, V.N. Statistical Learning Theory, AT\&T Research Laboratories, A Wiles Interscience Publication, John Wiley \& Sons Inc, 1998. 740 p.

[22] MENYHÁRT, J. Electric Voltage Measuring with Arduino Device, (in Hungarian) Hadmérnök Katonai Müszaki Tudományok Online, 2014, Vol. 4, p. 169-178.

[23] MENYHÁRT, J. Concept of an UGV With Arduino Device, Hadmérnök Katonai Müszaki Tudományok Online, 2014, Vol. 2, p. 140-148.

[24] JOHANYÁK, ZS.CS., KOVÁCS, SZ. On the Right Selection of the Fuzzy Membership Function, (in Hungarian) A GAMF Közleményei, Kecskemét, Hungary, 2004, Vol. 19, p. 73-84.

[25] HAN, J., MORAGA, C. The Influence of the Sigmoid Function Parameters on the Speed of Backpropagation learning, Computational Models of Neurons and Neural Nets, From Natural to Artificial Neural Computation, 2005, vol. 930, p. 195-201.

[26] GIBBS, M.N., MACKAY, D.J.C. Variational Gaussian process classifiers, IEEE Transactions on Neural Networks, 2000, vol. 11, Issue 6, 2000, p. 1-12.

[27] HEEGER, D. The logistic function, handsout, [on line] [cited: 2016.09.12.]

Available from: <http://www.cns.nyu.edu/ david/courses/perceptionLab/Handouts/LogisticHandout.pdf> 